\title{
Perceptions Held by Obese Children and their Parents: Implications for Weight Control Intervention
}

\author{
Karen C. Uzark, RN, PhD \\ Marshall H. Becker, MPH, PhD \\ T.E. Dielman, MA, PhD \\ Albert P. Rocchini, MD \\ Victor Katch, EdD
}

The study was designed to identify some of the psychosocial barriers to compliance in a hospital-based weight control intervention program for adolescents. Forty obese adolescents, 10 to 16 years of age, and their parents were surveyed prior to participation in a behavioral change weight control program at a major teaching hospital. Significant correlations were obtained between weight loss outcome and six factors. In obese adolescents, weight loss was significantly associated with their beliefs regarding: (1) personal control over weight, (2) barriers or difficulty of losing weight, (3) medical problems as a cause of their obesity, (4) family problems as a cause of their obesity, and (5) perceived willingness of family members to diet. It is suggested that greater. weight loss in children who perceived more barriers/difficulty and less family willingness to diet may reflect the importance of having realistic expectations related to behavioral compliance. In addition, a positive parental attitude or expectation that the child was less likely to be overweight in the future was associated with greater weight loss compliance. Other parental health beliefs, however, did not generally predict the child's weight loss response to the intervention. The findings lend support to the significance of the adolescent's beliefs regarding weight and family support in explaining weight loss response to a behavioral change intervention program.

Childhood obesity is a prevalent health problem associated with the development of serious deleterious long-term physical and psychosocial consequences. In the Framingham study, a longitudinal study of risk factors for cardiovascular disease, investigators

Karen C. Uzark and Albert P. Rocchini are with the Division of Pediatric Cardiology, C.S. Mott Children's Hospital, University of Michigan Medical Center.

Marshall H. Becker is with the Department of Health Behavior and Health Education, University of Michigan School of Public Health.

TE Dielman is with the Department of Postgraduate Medicine, University of Michigan.

Victor Katch is with the Division of Physical Education, University of Michigan.

Address reprint requests to Karen $\mathrm{C}$. Uzark, $\mathrm{RN}, \mathrm{PhD}$, Division of Pediatric Cardiology, C.S. Mott Children's Hospital, University of Michigan, Ann Arbor, MI $48109-$ 0204. 
concluded that, aside from not smoking, "reduction of overweight is probably the most important hygienic measure ... a available for the control of cardiovascular disease" (p. 140). ${ }^{1}$ Unfortunately, data reveal that more than $80 \%$ of obese adolescents become obese adults, ${ }^{2,3}$ suggesting that current weight control efforts for obese children are insufficient and/or ineffective. While childhood obesity is a multifaceted problem affected by genetic, physiologic, social, and economic variables, ${ }^{4}$ it is often the direct result of maladaptive attitudes and behaviors which lead to over-consumption and/or underactivity. To understand and facilitate compliance with interventions directed at changing the eating or exercise behaviors of obese children and adolescents, it is necessary to examine the attitudes and beliefs which contribute to these behaviors.

Considerable research has been conducted on the relationship between the health beliefs and health-related behaviors of adults. A recent review of 46 studies relevant to the Health Belief Model revealed that "perceived barriers" was the most powerful health belief dimension across various study designs and behaviors of adults. ${ }^{5}$ In a study of the model's ability to explain and predict mothers' compliance with a dietary regimen for their obese children, Becker and associates ${ }^{6}$ found significant correlations between major dimensions of the model and weight loss. Research by Costanzo and Woody ${ }^{7}$ has also revealed that parents' preconceptions about the nature of their child's weight problem are influenced by the sex of their children. Overweight in boys was seen as associated with less exercise, less emotionality, less social involvement, and pronounced food preferences. In contrast, greater overweight in girls was associated with greater influence of moods on eating, more parental restraint of eating. more emotionality, and greater peer rejection. It seems that parents of obese girls were relatively more inclined to see the child's obesity behavior in terms of problematic emotionally-driven eating behavior, and to assume an active role in restraining and redirecting that behavior. ${ }^{\text {? }}$

In the previously cited study which focused upon the mothers' health motives and perceptions as predictors of her child's weight loss. Becker et al. ${ }^{6}$ noted that mothers of older children were better compliers. It was suggested that older children use their extra control to adhere to the diet, possibly in response to peer pressures and the social desirability of losing weight. Perhaps with older children and adolescents who have somewhat greater control over their own behavior, there is more opportunity for their personal health beliefs to have an impact. Natapoff ${ }^{8}$ reviewed considerable evidence indicating that children's health beliefs begin to differentiate into a coherent belief system at approximately nine years of age, a time which corresponds well with Piaget's concrete operational period. Several studies have shown a stabilization of health beliefs around ten or eleven years of age. ${ }^{9-11}$ Health is salient to many adolescents $^{12}$ and Gochman ${ }^{9}$ has shown that the relationship between children's perceptions of vulnerability to health threats and potential health behavior was influenced by the degree of perceived internal control and the salience of health to the child.

While health beliefs are often significant predictors of health behaviors in adult populations, the relationship between health beliefs and preventive health behaviors in younger populations may be somewhat limited. ${ }^{11,13}$ This may be due to the amount of parental control and to relatively less "future-orientation" which only gradually increases during later childhood and adolescence. Dielman and associates ${ }^{11}$ found that two areas of children's preventive health behavior, cigarette smoking and snacking between meals, were subject to the influence of parental health behavior and, to a 
lesser extent, parental health beliefs. While it is suggested that parental health beliefs are a more distal influence. operating via their influence on parental behavior, a significant relationship was reported between these parental beliefs and the health beliefs of their children.

To understand adolescent compliance with a behavioral weight-control intervention, it is proposed that the following important psychosocial factors be examined: parental attitudes and beliefs regarding health, weight. and diet; the obese adolescent's attitudes and beliefs regarding health, weight, and diet; and perceptions or characteristics related to family support of the weight-control intervention.

\section{METHODS}

This prospective study was conducted in the Pediatric Cardiology Clinic at a major teaching hospital over a two year period that began in April, 1983. Data describing the attitudes and beliefs of obese children and their parents were obtained in conjunction with a larger research project investigating the physiologic effects of diet and exercise on weight loss in obese children (NIH No. AM30989). Obese subjects were recruited via referral initiated by the parent. teacher, physician, nurse, or self in response to a written notice printed in the local newspaper and mailed to local health care facilities. For admission to the program, subjects were required to satisfy three obesity criteria: 1) weight for height and age greater than the 75 th percentile of the HANES surveyU.S. Department of Health, Education and Welfare, ${ }^{14}$ 2) triceps and subscapular skinfold thickness greater than the 80th percentile for age by HANES criteria; and 3) percent fat greater than the 80th percentile for age. Consent was obtained from both parent and child.

Sociodemographic and other obesity-relevant characteristics of the participants are presented in Table 1. Children ranged in age from 10 to 16 years (mean=13.1) and were without physical illness that would require drug therapy or which would prohibit dietary restriction or exercise. Initial severity of obesity ranged from $5 \%$ to $157 \%$ overweight, above the minimum admission criterion described for this study. There were 28 girls and 12 boys; the sample was predominantly Caucasian, and six children lived with a single parent (mother). Ninety-five percent of the children lived with at least one overweight family member. Twenty-five $(62.5 \%)$ of the children had previously been on a weight-loss diet, and $33(82.5 \%)$ had previously experienced parental use of food as a reward.

\section{Weight Loss Intervention}

A behavior modification program was implemented to achieve weight loss through changes in eating and exercise behaviors. During weekly one-hour group sessions, the children and adolescents learned about good nutrition, more appropriate eating and exercise behaviors, and nonfood ways of responding to their environment. Maximum group size was 10 participants. Contingency contracts were used to monitor problem behaviors which the adolescent was working on changing from week to week. Each adolescent accumulated points for complying with various components of the behavioral program, (e.g., keeping food records and contracts earned five points per day.) 
Table 1. Characteristics of Obese Children.

\begin{tabular}{|c|c|c|}
\hline Characteristics & Number & $\%$ \\
\hline $\begin{array}{l}\text { Age (years) } \\
\quad \text { Mean }=13.1 \\
\text { Range }=10-16\end{array}$ & & \\
\hline $\begin{array}{l}\text { Sex } \\
\text { Female } \\
\text { Male }\end{array}$ & $\begin{array}{l}28 \\
12\end{array}$ & $\begin{array}{l}70.0 \\
30.0\end{array}$ \\
\hline $\begin{array}{l}\text { Severity of Obesity }(>75 \% \text { ile }) \\
\text { Mild }(5-25 \%) \\
\text { Moderate }(26-99 \%) \\
\text { Severe }(>100 \%)\end{array}$ & $\begin{array}{r}16 \\
21 \\
3\end{array}$ & $\begin{array}{r}40.0 \\
52.5 \\
7.5\end{array}$ \\
\hline $\begin{array}{l}\text { Age at Onset of Obesity } \\
\text { Infancy to } 5 \text { years } \\
\text { Childhood } \\
\text { Adolescence }\end{array}$ & $\begin{array}{r}14 \\
19 \\
7\end{array}$ & $\begin{array}{l}35.0 \\
47.5 \\
17.5\end{array}$ \\
\hline Previous Diet & 25 & 62.5 \\
\hline $\begin{array}{l}\text { Education-Parent } \\
\text { Some High School } \\
\text { High School Grad } \\
\text { College Grad }\end{array}$ & $\begin{array}{r}4 \\
24 \\
12\end{array}$ & $\begin{array}{l}10.0 \\
60.0 \\
30.0\end{array}$ \\
\hline $\begin{array}{l}\text { Marital Status-Parent } \\
\text { Married } \\
\quad \text { Single }\end{array}$ & $\begin{array}{r}34 \\
6\end{array}$ & $\begin{array}{l}85.0 \\
15.0\end{array}$ \\
\hline $\begin{array}{l}\text { Income (per year) } \\
\quad<\$ 10,000 \\
\quad \$ 10,000-19,999 \\
>\$ 20.000\end{array}$ & $\begin{array}{r}3 \\
9 \\
28\end{array}$ & $\begin{array}{r}7.5 \\
22.5 \\
70.0\end{array}$ \\
\hline $\begin{array}{l}\text { Proportion of overweight family memb } \\
\quad \begin{array}{l}1-50 \\
51-99 \\
100\end{array}\end{array}$ & $\begin{array}{r}2 \\
15 \\
17 \\
6\end{array}$ & $\begin{array}{r}5.0 \\
37.5 \\
42.5 \\
15.0\end{array}$ \\
\hline Prior parental use of food as a reward & 6 & 82.5 \\
\hline
\end{tabular}

Accumulation of points coupled with weight loss was then converted to monetary reinforcers given on a regular schedule, (e.g., 200 points and four pounds lost was worth $\$ 1.50$ ). Separate meetings were held with the parents periodically to provide nutrition education and specific instructions about reinforcement, altering the food environment, and maintaining proper attitudes.

The dietary component of this intervention program was designed to provide an acceptable dietary pattern which contained the necessary nutrients to promote growth while allowing for a weight loss of one to two pounds per week. A diet and weight loss prescription was determined for each adolescent. Consistent with the calorie level prescribed, a meal plan was developed using a modification of the American Dietetic Association's calorie exchange program. 


\section{Design and Measures}

Before participating in the weight loss intervention program, each subject and his/ her parent were administered a questionnaire assessing characteristics and beliefs/perceptions related to health, weight. and diet. The questionnaire was based on an instrument previously utilized by Becker et al. ${ }^{6}$ Modifications in the wording of questions were necessary for subject interviews since only parents had been surveyed in the earlier study. The questionnaires were pilot-tested on a group of 18 obese adolescents and their parents who had previously participated in the weight loss program. Further adjustments were made where questions were unclear or confusing, or where desired information was not elicited by the question. Most questions assessing a particular belief or attitude were scored on a six-point Likert-type scale.

Psychosocial variables assessed included: perceived threat of obesity, perceived barriers or difficulty of losing weight. feelings of control over weight, obesity attributions, and family support network factors. Items relating to the perceived threat posed by obesity were combined into an index. Ten items regarding the perceived severity of obesity as well as perceived susceptibility to, and severity of, the consequences of obesity were included. The index was comprised of "threat variables" which were identified as predictive of weight loss and/or appointment-keeping in the study by Becker et al. ${ }^{6}$ With regard to the internal consistency of the index, analysis of interitem reliability yielded alpha coefficients of 0.74 for parents $(N=40)$ and 0.69 for children $(N=40)$. "Perceived barriers" to compliance or weight control was measured by the amount of difficulty the subject/parent felt there was in order "to do something to help this overweight problem." Perception of personal control over weight was measured by amount of agreement/disagreement with the statesments "sometimes no matter what you do, you can't lose weight" and "there isn't much anyone can do about how much he weighs" ( $r=0.418$ for parents and $r=0.083$ for children). Each of eleven perceived causes of, or reasons for, obesity was also rated by the subject/parent to identify any specific obesity attribution of significance. Three separate dimensions of family support were assessed: "instrumental support," as measured by number of obese family members (modeling) and willingness of family members to diet as perceived by the child; "emotional support," as measured by the proportion of family members the adolescent perceived would encourage weight loss efforts; and "normative or appraisal support," as measured by the parent's attitude or expectation regarding the child's weight control.

Prior to the intervention, anthropometric measurements were also obtained and in. cluded weight, height, skinfold measurements, and body composition determinations (by hydrostatic weighing). Weight was subsequently measured at each behavior therapy session using a beam balance scale with the subject in street clothes and without shoes. Weights were obtained and recorded by a staff nurse in the clinic. Using a stabilometer, height was again measured to the nearest $0.1 \mathrm{~cm}$ approximately 20 weeks after the intervention was initiated. Subjects who dropped out of the intervention program prior to 20 weeks were requested to return to the clinic for measurement at that time. The last available height and weight (at 16-19 weeks) was considered the post intervention (time 2) measurement if a measure at 20 weeks could not be obtained.

While weight loss is an imperfect measure of program compliance because of 
biological variations in the response of individuals to diet and exercise, it remains the most important outcome. The obese subjects were, of course, overweight to varying extents, and were also growing in height at different rates. In an at tempt to achieve some standardization across subjects, the study's major dependent outcome variable was the change in percent overweight (greater than the 75 th percentile weight for height) 20 weeks after initiation of the intervention (time 2):

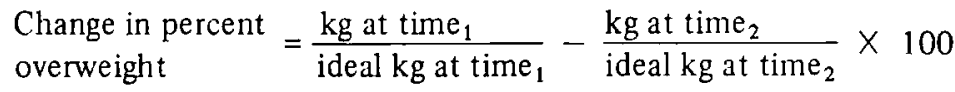

\section{RESULTS}

\section{Health Beliefs}

Associations between the health beliefs of the obese children and health beliefs of their parents are presented in Table 2 . The only significant positive correlation between parents and children is with respect to beliefs about the threat of obesity. Both parents $(X=4.44)$ and obese children $(X=4.04)$ tended to report at least moderate levels of threat.

However. significant negative associations were found between the child's beliefs regarding the threat of obesity and parental perception of personal control. and between the parent's perception of barriers or difficulty and the child's perception of personal control over weight. Children feel less personal control over weight as the parents perceive more barriers related to management of the child's weight problem.

While there were no significant correlations among parental health beliefs. it can be seen from Table 2 that for the child. perception of the threat of obesity is positively associated with perception of barriers to weight control and negatively associated with feelings of personal control over weight. Children who view obesity as a greater threat also tend to perceive more barriers to weight control and feel they have less personal control over their weight problem. There was no association, however, between beliefs about barriers and perception of personal control (or previous diet attempts). It is interesting that obese females tended to perceive greater barriers to weight control than did male subjects $(t=1.75,0.05<p<0.1)$.

Associations between health beliefs and compliance or weight loss outcome are presented in Table 3 . There was a significant association between the child's beliefs regarding personal control over weight and the weight loss outcome. As hypothesized, poor weight loss was related to decreased feelings of personal control over weight. There was also a significant pusitive association between the child's beliefs regarding barriers or the difficulty of losing weight and weight loss outcome. Obese subjects who felt it would be most difficult to control their weight were most successful. Since there was little variance in the threat measure in this sample, this index did not digtinguish compliers from noncompliers. No parental health belief was significantly associated with weight loss outcome. Clearly, the child's health beliefs regarding obesity were better predictors of weight loss than parental health beliefs. 


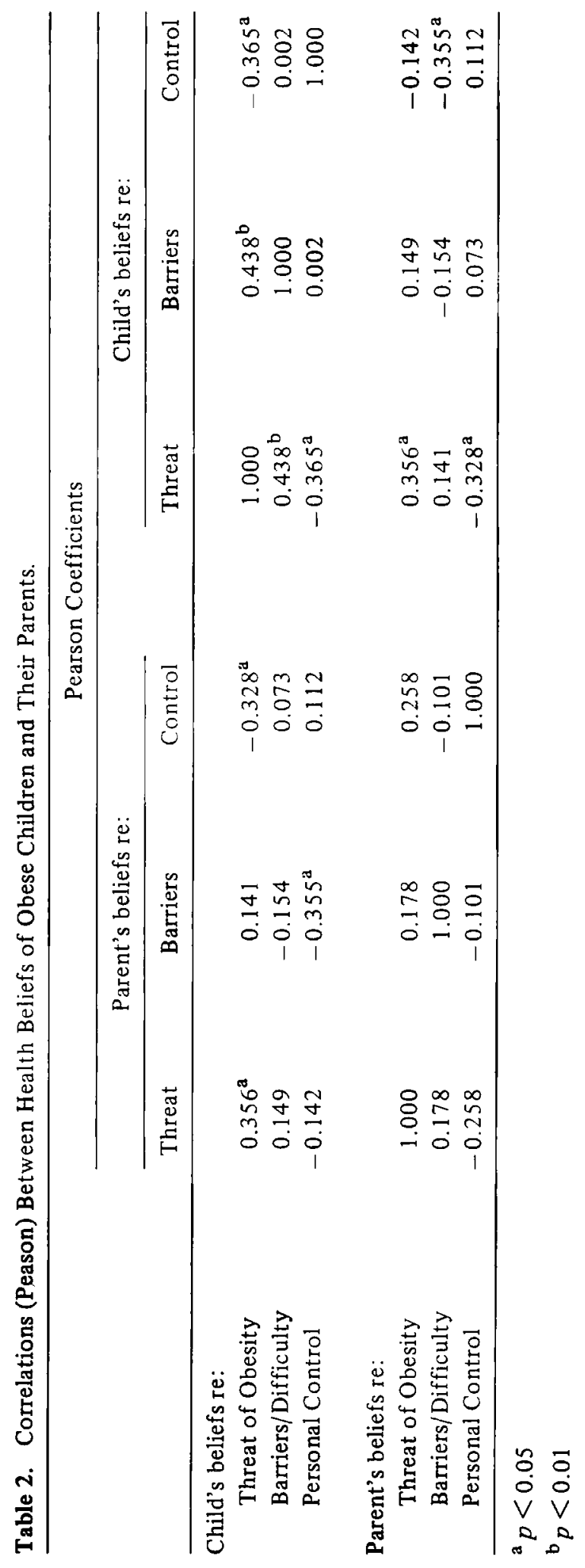


Table 3. Correlations (Pearson) Between Health Beliefs and Outcome.

\begin{tabular}{lc}
\hline \multicolumn{2}{c}{ Pearson Coefficients } \\
\hline $\begin{array}{c}\text { Weight Loss } \\
(\%)\end{array}$ \\
\hline Child's Beliefs Re: & -0.036 \\
Threat of Obesity & $0.363^{\mathbf{a}}$ \\
Barriers/Difficulty & $0.387^{\mathbf{a}}$ \\
Personal Control & \\
& \\
Parent's Beliefs Re: & 0.037 \\
Threat of Obesity & 0.226 \\
Barriers/Difficulty & 0.085 \\
Personal Control & \\
\hline a $p<0.05$ &
\end{tabular}

Table 4. Mean Scores and Correlations Among Obesity Attributions of Children and Parents (Scale values for attributions range from $1=$ not at all to $6=$ completely.).

\begin{tabular}{|c|c|c|c|c|c|}
\hline \multirow{2}{*}{ Attributions } & \multicolumn{2}{|c|}{ Children } & \multicolumn{2}{|c|}{ Parents } & \multirow{2}{*}{$\begin{array}{c}\text { Pearson } \\
\text { Coefficients }\end{array}$} \\
\hline & Mean & S.D. & Mean & S.D. & \\
\hline Bad eating habits & 4.20 & 1.36 & 4.63 & 1.08 & 0.000 \\
\hline $\begin{array}{l}\text { Can't resist certain fattening } \\
\text { foods }\end{array}$ & 3.22 & 1.51 & 4.40 & 1.15 & 0.301 \\
\hline Foods available in home & 2.85 & 1.33 & 2.98 & 1.37 & 0.153 \\
\hline Boredom & 2.82 & 1.65 & 3.38 & 1.48 & 0.206 \\
\hline Lack of exercise & 2.73 & 1.55 & 4.07 & 1.54 & $0.469^{\mathrm{b}}$ \\
\hline Eating away from home & 2.43 & 1.26 & 2.92 & 1.46 & 0.213 \\
\hline Influence of family & 1.93 & 1.35 & 2.30 & 1.29 & 0.073 \\
\hline Family problems & 1.83 & 1.20 & 1.95 & 1.18 & $0.340^{\mathrm{a}}$ \\
\hline Nervous tension & 1.80 & 1.31 & 2.33 & 1.29 & $0.436^{\mathrm{b}}$ \\
\hline School problems & 1.78 & 1.21 & 1.82 & 1.08 & 0.011 \\
\hline Medical problems & 1.23 & 0.80 & 1.73 & 1.30 & $0.529^{\mathrm{b}}$ \\
\hline
\end{tabular}

${ }^{\mathrm{a}} p<0.05$

${ }^{\mathrm{b}} p<0.01$

\section{Attributions}

Obese subjects and their parents rated 11 possible causes of the child's obesity. Mean scores and correlations between obesity attributions of the children and parents are presented in Table 4. Both parents and children thought that eating behaviors, (i.e., bad eating habits and inability to resist certain fattening foods), were the major causes of obesity. Children were more likely than parents to rate the types of foods available in the home as a cause of their obesity relative to other possible causes while parents were more likely to feel that lack of exercise contributed to the child's obesity. Although there were no significant differences between the attributional beliefs 
Table 5. Correlations (Pearson) Between Obesity Attributions and Outcome Measure.

\begin{tabular}{lrr}
\hline & \multicolumn{2}{c}{ Weight Loss } \\
\cline { 2 - 3 } & Child & Parent \\
\hline Child/Parent Attribution of Obesity to: & $0.380^{\mathbf{a}}$ & 0.068 \\
Medical problems & 0.044 & -0.034 \\
Bad eating habits & 0.061 & 0.001 \\
Lack of exercise & -0.177 & 0.056 \\
Nervous tension & -0.164 & -0.086 \\
Boredom & $-0.372^{\mathbf{a}}$ & 0.007 \\
Family problems & -0.238 & $-0.292^{\mathbf{a}}$ \\
Influence of family & -0.160 & $-0.316^{\mathbf{a}}$ \\
Foods available in home & -0.144 & -0.158 \\
Eating away from home & -0.206 & -0.015 \\
Problems with school & -0.061 & -0.123 \\
Can't resist certain fattening foods & & \\
\hline
\end{tabular}

${ }^{a} p<0.05$

of obese boys and girls, parents of female subjects felt that lack of exercise $(t=2.90$. $p(0.01)$, boredom $(t=2.63, p=0.01)$ and inability to resist certain fattening foods $(t=2.13, p<0.05)$ were more likely causes of their child's obesity. There were significant correlations between the parent's and the child's beliefs with respect to four of the eleven obesity attributions: lack of exercise, family problems, nervous tension, and medical problems. (Medical problems were not generally regarded by either parents or children, however, as a likely cause of the obesity.) Other than the associations presented in Table 4 , it is of interest that the highest correlation within beliefs regarding attributions for both parents and children, was between family problems and nervous tension, with Pearson's correlations of 0.637 for parents and 0.634 for children, $(p<0.001)$.

Correlations between obesity attributions and weight loss are presented in Table 5. While few children attributed their obesity to medical problems, this attributional belief was positively associated with weight loss outcome, contrary to the direction hypothesized. There was a significant negative association between the child's attribution of obesity to family problems and weight loss. It is of further interest that this attribution was found to be strongly correlated with the frequency of family problems $(r=0.543, p(0.001)$ and, as previously mentioned, with the attribution of obesity to nervous tension $(r=0.634, p(0.001)$ which was also highly correlated with the frequency of family problems $(r=0.596, p(0.001)$. Children who attributed their obesity to family problems, or perhaps family stress, lost less weight.

Parental attributions of their child's obesity to the kinds of foods available in the home, and to the influence of family members, were negatively associated with weight loss outcome. These attributions also seem to be related to the frequency of family problems. Additional analyses reveal that attribution to the influence of family members is positively correlated with attribution to family problems $(r=0.384, p=0.02)$. with both attributions positively correlated with the frequency of family problems $(r=0.364,0.493, p<0.03)$. Poor weight loss is related to the parent's perception that both family members and foods available in the home environment contribute to their child's obesity. 
Table 6. Correlations Between Family Support Network Characteristics and Outcome Measure.

\begin{tabular}{lc}
\hline \multicolumn{2}{c}{ Pearson Coefficients } \\
\hline
\end{tabular}

${ }^{\mathrm{a}} p<0.05$

\section{Family Support Network}

Relationships between family support network characteristics and the dependent variable measures are presented in Table 6 . Perceived willingness of family to diet was negatively associated with weight loss compliance, contrary to the direction hypothesized. Children who perceived more willingness of family members to diet lost less weight. When this variable was multiplied by the proportion of obese family members to create the instrumental support index, the association with weight loss was no longer significant. (There was no significant correlation between the preintervention perceived willingness of family members to diet and the perceived willingness of family members to diet following the intervention $(N=25)$.) There was also no significant association between familial obesity and weight loss compliance.

Emotional support from family members, as perceived by the child, was not significantly correlated with weight loss. However, weight loss was positively associated with the parental belief that their child was not likely to be overweight in the future $(r=0.361), p<0.05)$. Children of parents who expressed a pessimistic or hopeless attitude regarding their child's obesity lost less weight, and such pessimism was also associated with greater familial obesity $(r=-0.320, p<0.05)$.

\section{DISCUSSION}

Bivariate relationships between the attitudes/beliefs of obese children'regarding weight/diet and some family support characteristics and subsequent weight loss outcome are summarized in Table 7. Based on this study's findings, it can be concluded that the health beliefs of obese adolescents are important factors in the explanation and prediction of weight loss response to a behavioral change weight control intervention. In obese children, 10 to 16 years of age, weight loss was significantly associated with their perceptions regarding: (1) personal control over weight, (2) barriers or difficulty of losing weight, (3) medical problems as a cause of their obesity, (4) family problems as a cause of their obesity, and (5) willingness of family members to diet. In general, the child's weight loss response was not directly correlated with parental health beliefs, although the parent's beliefs may have influenced the child's perceptions and may reflect the relative supportiveness of the home environment. 
Table 7. Summary of Bivariate Relationships for Predictors of Weight Loss

\begin{tabular}{|c|c|c|}
\hline \multicolumn{3}{|l|}{ Pearson Coefficients } \\
\hline \multirow{2}{*}{ Variable } & \multicolumn{2}{|c|}{$\begin{array}{c}\text { Weight Loss } \\
(\%)\end{array}$} \\
\hline & Correlation & $p$ \\
\hline \multicolumn{3}{|l|}{ Health Beliefs: } \\
\hline Threat of obesity & -0.036 & NS \\
\hline Personal control & 0.387 & 0.01 \\
\hline Barriers/difficulty & 0.363 & 0.02 \\
\hline \multicolumn{3}{|l|}{ Obesity Attributions: } \\
\hline Medical problems & 0.380 & 0.02 \\
\hline Family problems & -0.372 & 0.02 \\
\hline \multicolumn{3}{|l|}{ Family Support Network Characteristics: } \\
\hline Instrumental support & -0.298 & NS \\
\hline -Perceived willingness family to diet & -0.372 & 0.02 \\
\hline Emotional concern & 0.132 & NS \\
\hline \multicolumn{3}{|l|}{ Appraisal support } \\
\hline -Parental attitude re: child's future obesity & 0.361 & 0.02 \\
\hline
\end{tabular}

As anticipated, children enrolled in the weight control intervention program regarded obesity as a significant threat to physical or psychological well-being. In these children, perception of personal control over weight was a significant factor in weight loss behavior. A perception of personal control over weight prior to participation in a behavioral change intervention may facilitate weight loss compliance. The child's control beliefs were not related to the child's age or to the actual severity of obesity. Children whose parents perceived greater threat and more barriers to weight control felt less personal control over weight. Perhaps parents who were more overwhelmed by their child's obesity communicated these beliefs to their children and thereby diminished the child's feelings of personal control over his/her weight. This suggests that parental beliefs may influence their children's beliefs. With respect to the child's weight loss behavior, however, the adolescent's personal health belief was clearly a more significant factor in predicting weight loss outcome than the parent's health belief. As postulated previously, in older children who have greater control over their own behavior in an expanded social environment, there may be more opportunity for the adolescent's personal health beliefs to have an impact on behavior.

"Barriers," or the appraised difficulty of weight control, was another important perception of the obese adolescent related to weight loss outcome. Their beliefs regarding barriers however did not appear to be directly related to the beliefs of their parents or to previous diet attempts. Obese children/adolescents who felt it would be more difficult to control their weight were most successful. Perhaps this was related to their more accurate expectations regarding their own role in compliance with the weight control regimen. Social forces direct many overweight adolescents to fad diets in the vain hope of achieving weight loss without difficult diet restrictions or behavior changes. Children enrolled in a weight control program who appreciate the difficulty of the personal behavior changes required may have high "self-efficacy," defined by 
Bandura ${ }^{15}$ as the conviction that one can successfully execute the behavior required to produce the outcome. In a recent review of research exploring the role of self-efficacy in achieving health behavior change among adults, self-efficacy appeared to be a consistent predictor of short-and long-term success for all health-related areas studied, including weight control. ${ }^{16}$ Furthermore. it was suggested that self-efficacy can be enhanced and that this enchancement is related to subsequent health behavior change.

Causal explanations of obesity. as perceived by the obese child. may also be important factors influencing weight loss behavior. Consistent with the findings of Edelman. ${ }^{17}$ obese children reported bad eating habits as the most likely cause of their obesity. Attributions of obesity to medical problems and to family problems were, however. more significant predictors of weight loss. Greater weight loss in children who attributed their obesity to medical problems may have been related to the setting in which the weight control intervention was offered. In a hospital-based intervention program. the perceived efficacy of the intervention and the credibility of the source of recommendations may have been enhanced. thus promoting compliance. This attributional belief was also strongly supported by their parents who may have reinforced confidence in a hospital-based intervention.

Poor weight loss outcome was associated with the obese child's attribution of his/her obesity to family problems. In addition to this important longitudinal relationship. cross-sectional analyses revealed that the child's attribution of their obesity to family problems was also highly correlated with the attribution of obesity to nervous tension. the frequency of family problems, and parental attribution of obesity to family problems. Thus. it appears that family stress may be an important factor in the treatment of obesity. It has been suggested that childhood obesity develops even in infancy when food is used for relief of various states of tension, ${ }^{18}$ and that later obesity may become a "padding" against a hostile, home environment. ${ }^{19}$ Overeating has been included among emotion-focused coping behaviors. ${ }^{20}$ It is therefore understandable that the specific attribution of obesity to family problems is negatively associated with weight loss, especially if alternative strategies for managing stress or coping with family problems are not provided.

Additional family-related detrimental effects on weight control may be seen in parental attribution data. Poor weight loss outcome was related to the parent's perception that foods available in the home environment and, to a lesser extent, family members. contributed to the child's obesity. Since parents largely control the quality and quantity of food in the home, this attributional belief suggests an unwillingness to provide some environmental control for the obese child. Obesity attributions of parents also suggest that parents of girls "blame," or attribute the obesity to the adolescent's personal behaviors-lack of exercise. boredom, inability to resist fattening foods-rather than on physical or environmental conditions. While these beliefs of parents were not directly associated with weight loss. they may be related to parenting behaviors which diminished the adolescent's self-efficacy beliefs regarding weight control.

Among the family support dimensions assessed in this study. only normative or appraisal support was positively correlated with weight loss. A positive parental attitude or expectation that the child was less likely to be overweight in the future was associated with greater weight loss. This family support variable did not rely on the child's perceptions of family support or beliefs, and therefore is perhaps a better indicator of actual family support offered. With respect to the measures of instrumental 
and emotional support. responses of the obese children may have been biased by the desire to avoid embarrassment when social support from family was lacking. The significant negative association between willingness of family members to diet (as perceived by the child) and weight loss may reflect the child's hopes or wishful thinking prior to participation in the intervention program. Children living with other obese family members might expect weight control to be a desirable goal for their entire family. Children who did not rely on family modeling or environmental support seem to be more successful in losing weight. perhaps again suggesting their greater feelings of self-efficacy. Children who expect instrumental and normative support from parents or family members might benefit more from a family-based behavior modification program as suggested by Epstein and associates. ${ }^{21}$

\section{CONCLUSIONS}

In summary. our data highlight the role played by the adolescent's beliefs regarding weight and family support in predicting weight loss regimen compliance. For obese adolescents, weight loss was significantly associated with their beliefs regarding: (1) personal control over weight; (2) "barriers" or difficulty of losing weight; (3) medical problems as a cause of their obesity; (4) family problems as a cause of their obesity; and (5) perceived willingness of family members to diet. In addition, "appraisal support" (parental expectation that the child was less likely to be overweight in the future) was associated with greater weight loss. Other parental health beliefs, however, did not generally predict the child's weight loss but may have influenced the children's beliefs regarding weight control.

Based on these findings, several recommendations for enhancing the effectiveness of behavioral change weight control interventions are proposed for consideration: (1) an assessment should be made of the attitudes and beliefs of the obese children and parents, especially with regard to their obesity attributions, personal control perceptions, and views concerning barriers to weight control (this information should be included in discussions with parents and children as a basis for identifying weight control needs); (2) an attempt should be made to increase feelings of control over weight by helping adolescents to focus on behaviors that are alterable (it may be especially important to include education in the development of problem-solving skills and stress management techniques); and (3) in addition to informing parents about nutrition and behavioral change strategies. family members may need education to enhance supportive interactions in the adolescent's social environment.

\section{References}

1. Kannel, WB, Gordon, T: Physiological and Medical concomitants of obesity: The Framingham study. In Bray G. (ed.), Obesity in America. U.S. Department of Health, Education, and Welfare, NIH Publication No. 79-359, 1979.

2. Charney, E, Goodman, HC, McBride, M, Lyon, B, Pratt R: Childhood antecedents of adult obesity. New England Journal of Medicine 295:6-9, 1976.

3. Collipp, PJ : Obesity in childhood, In Stunkard AJ (ed.), Obesity. Philadelphia, W.B. Saunders Company, 1980. 
4. LeBow, MD: Child Obesity-A New Frontier of Behavior Therapy. New York: Springer, 1984.

5. Janz, NK and Becker MH: The health belief model: A decade later. Health Education Quarterly 11:1-47, 1984.

6. Becker, MH, Maiman, LA, Kirscht, JP, Haefner, DP, Drachman RH: The health belief model and prediction of dietary compliance: A field experiment. Journal of Health and Social Behavior 18:348-366, 1977.

7. Costanzo, PR Woody, EZ: Parental perspectives on obesity in children: The importance of sex differences. Journal of Social and Clinical Psychology 2:305-313, 1984.

8. Natapoff, JN: A developmental analysis of children's ideas of health. Health Education Quarterly 9:34-45, 1982.

9. Gochman D: Some correlates of children's health beliefs and potential health behavior. Journal of Health and Social Behavior 12:148-154, 1971.

10. Lewis, CE, Lewis, MA, Lorimer, A, and Palmer, BB: Child-initiated care: The use of school nursing services by children in an "adult free" system. Pediatrics 60: 499-507, 1977.

11. Dielman, TE, Leech, S, Becker, MH, Rosenstock, I, Horvath, W, Radius, SM: Parental and child health beliefs and behavior. Health Educaion Quarterly 9:6077, 1982.

12. Radius, SM, Dielman, TE, Becker, MH. Rosenstock, IM, Horvath, WJ: Adolescent perspectives on health and illness. Adolescence 15:375-384, 1980.

13. Kegeles, SS, Lund, AK: Adolescents' health beliefs and acceptance of a novel preventive dental activity: Replication and extension. Health Education Quarterly 9:96-112, 1982.

14. United States Department of Health, Education and Welfare: NCHS Growth Curves for Children. (The Hanes Data) Vital and Health Statistics: Series 11, Publication No. (PHS) 78-1650, 1977.

15. Bandura, A: Self-efficacy: Toward a unifying theory of behavioral change. Psychological Review 84:191-215, 1977.

16. Strecher. VJ, DeVellis, BM, Becker, MH, Rosenstock, IM: The role of self-efficacy in achieving health behavior change. Health Education Quarterly 13:73-92, 1986.

17. Edelman B: Developmental differences in the conceptualization of obesity. Journal of American Dietetic Association 80:122-127, 1982.

18. Bruch, H: Emotional aspects of obesity in children. Pediatric Annals 4:91-99, 1975.

19. Kornhaber, A, Kornhaber E: Psychopathological obesity types in children and their treatment. In Collipp, PJ (ed.). Childhood Obesity. Littleton, PSG Publishing Company, Inc., 1980.

20. Moos, RH, Billings, AG: Conceptualizing and measuring coping resources and processes. In Goldberger. L and Breznitz S (eds.), Handbook of Stress: Theoretical and Clinical Aspects. New York, Free Press, 1982.

21. Epstein, LH, Wing RR, Koeske, R, Andrasik, F, Ossip, DJ: Child and parent weight loss in family-based behavior modification programs. Journal of Consulting and Clinical Psychology 49:674-685, 1981. 